\title{
RELAÇÕES DE AUTORIA ENTRE TIA NASTÁCIA E EMÍLIA EM MONTEIRO LOBATO
}

\author{
Ana Luísa Macedo Raimundo \\ Mestre em Linguística pela Universidade Federal de Goiás (UFGO) \\ analuisaletras@yahoo.com.br
}

\section{RESUMO}

Este artigo analisa a possibilidade de uma leitura das personagens Tia Nastácia e Emília, presentes nas narrativas infantis/juvenis de Monteiro Lobato. Neste estudo investigamos uma analogia entre essas personagens que possibilitam enxergar em sua relação uma situação de autor e obra, já que Nastácia é responsável pela confecção de Emília na narrativa. A partir deste olhar e das concepções da Análise do Discurso de Linha Francesa, discutimos, baseados nos conceitos de autor/obra trabalhados por Bakhtin/Volochínov (2014) e Foucault (2002), como Nastácia se encontra, dentro das narrativas, na posição-autor na produção da boneca Emília. Com isso, procuramos contribuir para um novo olhar interpretativo sobre essas personagens e as narrativas infantis lobatianas.

Palavras-chave: Tia Nastácia; Emília; autoria; Bakhtin; Foucault.

\begin{abstract}
This article analyzes the possibility of a reading of the characters Aunt Nastácia and Emília from the Saga of the Sitio do Picapau Amarelo by Monteiro Lobato. In this study we investigate an analogy between these characters that makes it possible to see in their relationship a situation of author and work, since Nastácia is responsible for the making of Emília in the narrative. From this look and from the conceptions of French School of Discourse Analysis, I discuss, based on the concepts of author / text explored by Bakhtin / Volochínov (2013-2014) and Foucault (2002), if Nastácia is in the author position in the production of the Emília doll. Through this effort, I intend to contribute to a new interpretive approach to these characters and children's narratives.
\end{abstract}

Keywords: Aunt Nastácia; Emília; authorship; Bakhtin; Foucault. 


\section{Introdução}

A autoria atribuída a um sujeito é fundamentada em relação à sua obra, assim para que um sujeito ocupe, nas relações sociais o papel, a função autor ele deve ser caracterizado como alguém que possibilitou a existência, circulação e funcionamento de determinados discursos em uma sociedade (FOUCAULT, 1969/2001), que apresente feitos originais e produções com um estilo individual (CHARTIER, 2012), esse estilo deve ser reconhecido através de uma imagem produzida por seus leitores e críticos, atribuindo-lhe uma personalidade (MAINGUENEAU, 2010) e, no caso da obra literária, a autoria se constitui no gesto de criação da personagem, ou seja, seu objeto estético (BAKHTIN, 2003).

Dessa forma, acreditamos ser possível entender como autoria o gesto de confecção da boneca Emília por Tia Nastácia no contexto interno das narrativas dos livros infantis/juvenis de Monteiro Lobato. Ou seja, no universo ficcional narrado, Nastácia apresenta características de autora, pois para Orlandi (2007), a autoria é entendida como um gesto, uma função dialógica de um sujeito que ao interpretar o seu contexto social, produz um texto, promovendo possibilidades interpretativas de sentidos. Assim, a autoria é um papel social assumido pelo sujeito, ou como Foucault (1969) observa em sua conferência de O que é um autor?, a autoria é uma função assumida pelo sujeito que garante a circulação, existência e funcionamento de certos discursos em uma sociedade. Ao discutir o autor-criador, Bakhtin (1997), coloca o autor em uma posição de princípio, produtiva e criadora. Nessa posição, ele reage às manifestações do herói numa relação dialógica e, assim, em interação, autor e herói são construídos.

A partir dessas concepções, a atribuição de autoria ao nome Monteiro Lobato é óbvia. Porém, ao analisarmos o universo de suas narrativas infantis e juvenis, nos depa- 
ramos com esse mesmo gesto de criação, possibilitado por ele, ao criar a personagem Tia Nastácia. Ela, até então, cozinheira do sítio, apresenta na dispersão da obra de Lobato, gestos que possibilitam enxergá-la em outra função longe do fogão, a função autor. Acreditamos que Nastácia apresenta todos os requisitos estabelecidos pelos teóricos que apoiam nossa pesquisa, menos a imagem de autoria (MAINGUENEAU, 2010).

Dessa forma, neste artigo apresentamos uma possível leitura e interpretação de uma relação autoral entre Tia Nastácia e Emília no interior das narrativas, no universo fantástico criado por Monteiro Lobato. Para isto, trazemos alguns enunciados das histórias, a partir dos quais acreditamos ser possível defender que há uma analogia entre as personagens; que, na posição de criadora de Emília, no contexto das narrativas, Nastácia imprime na boneca uma representação humana, um texto seu, todo "um discurso que deve ser recebido de uma certa maneira e que deve, em uma certa cultura, receber um certo estatuto" (FOUCAULT, 2002, p. 45), pois, em sua função-autora, ela invoca e indica toda uma memória coletiva representada nas rupturas promovidas pela boneca.

A leitura do livro Emília no país da gramática (2009) culminou na mudança de nosso olhar para a relação das duas personagens, pois no trecho que segue, Emília promove uma analogia entre elas:

E os Nomes Abstratos sãos os que marcam coisas que a gente quer que existam, ou imagina que existem, como BONDADE, LEALDADE, JUSTIÇA, AMOR.

- E também DINHEIRO - sugeriu Emília.

- DINHEIRO é Concreto, porque dinheiro existe - contestou Quindim.

- Para mim e para Tia Nastácia é abstratíssimo. Ouço falar em dinheiro, como ouço falar em JUSTIÇA, LEALDADE, AMOR; mas ver, pegar, cheirar e botar no bolso dinheiro, isso nunca (LOBATO, 2009, p. 32). 
Dessa forma, passamos a investigar se isso ocorria em outros momentos das narrativas, o que foi positivo e, por isso, buscamos compreender a relação entre as duas personagens no início da saga:

Na casa ainda existem duas pessoas - tia Nastácia, negra de estimação que carregou Lúcia em pequena, e Emília, uma boneca de pano bastante desajeitada de corpo. Emília foi feita por tia Nastácia, com olhos de retrós preto e sobrancelhas tão lá em cima que é ver uma bruxa. Apesar disso Narizinho gosta muito dela (LOBATO, 2005, p. 7).

A relação entre as personagens se caracteriza por um jogo de oposição e proximidade, promovendo um efeito de sentido como se as duas fossem dois lados diferentes da mesma moeda. No processo de confecção de Emília, Nastácia acaba criando um "outro" de si mesma, apresentando marcas que remetem a sua própria imagem. Nesse trecho, por exemplo, a "feiura" de Emília é destacada, o que pode refletir a "feiura" da autora, a qual não se encaixa no padrão de beleza social da época. Nessa comparação icônica, ou seja, da imagem das duas, o jogo de autoria entre Nastácia e Emília se constitui inicialmente sendo a boneca sua imagem e semelhança.

Ainda no mesmo trecho, temos uma locução conjuntiva adversativa "apesar disso". Essa locução inicia uma oração que apresenta o sentido de que por mais que Emília seja feia, Narizinho ainda assim gosta muito dela. Há aqui uma marca bastante preconceituosa, pois por causa de sua feiura, Emília não mereceria que os outros a apreciassem. Essa oposição trazida pelo uso da locução conjuntiva explicita como a imagem é importante nas relações sociais. Assim, o fato de Nastácia criar Emília "feia", pode comprovar que ela se projeta na boneca e denuncia sua condição de ser inferior, que, muitas das 
vezes, não merecia o apreço das outras pessoas. Para fundamentar nosso posicionamento, é preciso esclarecer a identidade de cada uma delas.

Nastácia é apresentada aos leitores da saga como "negra de estimação" (LOBATO, 2005, p. 7) e cozinheira do Sítio. Esse status consiste em um escravo liberto depois de anos de servidão. Assim, temos na forma como Nastácia é identificada não um sujeito, mas um objeto, uma função. Ela se encontra numa posição subalterna e sem projeção na narrativa. No contexto de sua publicação, início do século $X X$, a abolição da escravidão tinha acontecido havia pouco tempo e, por isso, os negros que permaneciam nas casas dos brancos eram apelidados dessa forma, "como se fossem da família". Assim, Nastácia é apresentada mais como uma função do que como um sujeito. Ela fica a maior parte do tempo na cozinha preparando quitutes que encantaram leitores de todo o Brasil, porém também participa de várias aventuras, mas sempre com pouco destaque e, quase sempre, demonstra muito medo e características supersticiosas diante de tudo. A personagem/função não enuncia com constância e quando o faz apresenta limitação, como mostra Veloso (2013), em sua dissertação Perfis femininos em livros infantis de Monteiro Lobato (1920-1940):

Dar voz a essa personagem torna-se complexo. Quem lê os livros de Monteiro Lobato apenas para fruição pode crer inclusive que sua fala é única e homogênea: "Credo!". Observa-se que, quando a profere, Tia Nastácia o faz sem conhecer a etimologia da palavra, reproduzindo o vocábulo sem conhecer seu valor histórico (VELOSO, 2013, p. 93).

Todavia, a cozinheira tem um dos livros da saga com seu nome no título e com suas histórias no recheio: Histórias de Tia Nastácia (2011). Nesse livro, ela, como personagem em destaque, passa a narrar para a turma do Sítio as histórias populares que lhe fo- 
ram contadas ao longo de sua vida. Mesmo aqui, Nastácia tem sua enunciação limitada, pois em diversos momentos é interrompida pelos meninos que criticam as narrativas ou a maneira como ela narra:

- Que história de contar sete é esta? - perguntou Emília quando a negra chegou ao fim. - Não estou entendendo nada.

- Mas isto não é para entender, Emília - respondeu a negra -. É da história. Foi assim que minha mãe Tiaga me contou o caso da princesa ladrona, que eu passo para diante do jeito que recebi. [...]

- Sim - disse dona Benta - Nós não podemos exigir do povo o apuro artístico dos grandes escritores. O povo... Que é o povo? São essas pobres tias velhas, como Nastácia, sem cultura nenhuma, que nem ler sabem e que outra coisa não fazem senão ouvir as histórias de outras criaturas igualmente ignorantes e passa-las para outros ouvidos, mais adulteradas ainda (LOBATO, 2011, p. 27).

Por esses exemplos, encontramos em Nastácia o estereótipo de um sujeito inferiorizado pelo narrador/autor, no caso o negro no Brasil depois da abolição da escravidão. No último parágrafo do trecho selecionado, temos uma descrição de Nastácia, representante do povo, como "pobres tias velhas", "sem cultura nenhuma", "nem ler sabe", "ignorantes". O uso da pluralização dos adjetivos e verbo demonstra a quantidade de "Nastácias" pelo país, ou seja, de negras de estimação, vindas da escravidão e que permaneceriam na condição objetivada de cozinheiras e domésticas, sem qualquer possibilidade de ascensão social, pois já estavam velhas e não pertenciam ao padrão estético da época. Sua condição é tão generalizada que, quando questionada pela incompreensão de sua história, ela mostra que a narrativa não é dela: "eu passo para diante do jeito que recebi". Ela se isenta de autoria e também não consegue explicar o sentido da narrativa, pois sua condição é só de passar, manter a tradição, ela não a questiona. Ela representa as mulheres das camadas populares com um conhecimento prático da vida, em oposição à dona 
Benta com todo seu conhecimento científico. Por isso, sua enunciação é marcada por uma linguagem coloquial, com problemas de concordância, desvios à norma padrão da língua e vocabulário limitado. Assim, por vezes, ela é questionada sobre a lógica do que enuncia pelos personagens do Sítio.

A variação linguística apresentada por seus personagens em suas narrativas retrata o engajamento de Lobato pela independência linguística brasileira que movimentou as primeiras décadas do século XX. Lobato lutou junto com os modernistas pela construção de uma identidade brasileira e, para ele, uma das principais questões era o idioma. Assim, sua obra é marcada pela variedade linguística e a crítica à gramática normativa (COX; LIMA, 2017). O autor, assim como os outros modernistas, enxergava a língua como uma grande marca de identidade social, por isso era preciso que o brasileiro se enxergasse na Literatura, se enxergasse na constituição de uma identidade nacional. Dessa forma, Lobato dá voz aos que até então não tinham uma e marca essa voz como ela era (é), ou seja, com a identidade linguística que as pessoas usam e se constituem.

Em contrapartida, temos Emília, a criaturinha-boneca que nasce muda das mãos de Nastácia e que, a partir do momento que enuncia, começa a promover uma inovação de ideias e rupturas de padrão, ganhando um espaço representativo significante nas narrativas lobatianas e na literatura brasileira. Segundo Bakhtin/Volochínov, a dialética que envolve o interior psíquico e o exterior social se dá por meio do ato de fala, da enunciação $(2014$, p. 67). É o fato de enunciar, sua capacidade de interagir por meio da linguagem, que dá à Emília novo papel social na atmosfera da narrativa, pois a insere na cadeia de interações sociais. Nessa nova perspectiva, a boneca, por meio de seus enunciados, apresenta seu posicionamento ideológico discursivo, pois "a palavra é o fenômeno ideológico por excelência" (BAKHTIN; VOLOCHÍNOV, 2014, p. 36). 
Nesse ponto - a enunciação - encontramos a primeira analogia entre as personagens. Esse aspecto assegura, em sua oposição, o fato de Nastácia imprimir em Emília, sua criação/texto, o que ela não conseguia fazer, a ruptura que ela, em sua condição de sujeito inferiorizado, não só no Sítio, mas ao longo da história do negro, não conseguia promover: enunciar de uma forma nova, que rompesse com tudo o que ela trazia de sua situação discursiva sócio-histórica. Sendo o texto de Nastácia, Emília é uma materialidade e espaço significante (ORLANDI, 2007, p. 60). Dessa forma, a boneca é constituída materialmente e apresenta, em sua relação com a exterioridade, outros textos (personagens e situações) e condições de produção (Nastácia e toda sua constituição discursiva; contexto), discursos que permitem o gesto de interpretação dela como enunciação de Nastácia. Nas palavras de Narizinho, a princípio dona da boneca e depois amiga e companheira de aventuras e descobertas, "as ideias de Emília hão de ser sempre novidades" (LOBATO, 2005, p. 20). Nessa perspectiva, por meio da enunciação, Nastácia se constitui em Emília, imprime na boneca, sua criação/texto, os discursos que a atravessam em toda sua condição histórica, como forma de ruptura, de quebra de tudo o que ela é. Emília é a potencialidade de ser de Nastácia.

Segundo Bakhtin, todas as formas de enunciação, de produção de textos, se dão por meio de gêneros discursivos relativamente estabelecidos em cada esfera da atividade humana, os quais apresentam um conteúdo, um estilo e construção composicional que refletem as condições e finalidades de cada esfera que o produziu e produz (BAKHTIN, 2003, p. 261). É então através desses gêneros que exercemos nossos gestos de autoria, num gesto de interpretação, relacionando nossa memória discursiva, interdiscurso (PÊCHEUX, 1995, p. 314) com a exterioridade, criando uma unidade discursiva na materialidade do texto (ORLANDI, 2007, p. 15). Ora, Emília é uma boneca, com imagem e propri- 
edades humanas, confeccionada pelas mãos de Nastácia, a partir de materiais de seu campo e situação social:

Emília, uma boneca de pano bastante desajeitada de corpo. Emília foi feita por tia Nastácia, com olhos de retrós preto e sobrancelhas tão lá em cima que é ver uma bruxa (LOBATO, 2005, p. 7).

- É porque é de pano, sinhá - explicou a preta - e dum paninho muito ordinário. Se eu imaginasse que ela ia aprender a falar, eu tinha feito ela de seda, ou pelo menos dum retalho daquele seu vestido de ir à missa (LOBATO, 2005, p. 21).

- Alimentação macelar, eu sei - disse a menina rindo-se da ciência do doutor. Tia Nastácia sabe aplicar esse remédio muito bem. Em dois minutos, com um bocado de macela e uma agulha com linha ela cura Emília para o resto da vida (LOBATO, 2005, p. 37).

Assim, podemos interpretá-la como um texto, um enunciado, materializado num gênero: boneca. Emília é o texto e Nastácia a autora, pois ela materializa nessa boneca (forma relativamente estável), todo um estilo próprio que a diferencia de todas as outras bonecas. Segundo Eco (1986), um texto é uma materialidade complexa, entremeada por espaços em brancos possibilitados por um autor-modelo, que prevê um leitor-modelo que atualizará os sentidos e discursos de seu texto. Dessa forma,

toda vez que usarmos termos como Autor e Leitor-Modelo, sempre entenderemos, em ambos os casos, tipos de estratégia textual. O LeitorModelo constitui um conjunto de condições de êxito, textualmente estabelecidas, que devem ser satisfeitas para que um texto seja plenamente atualizado no seu conteúdo potencial (ECO, 1986, p. 45). 
Com isso, é possível pensar Emília, enquanto texto, pensada por sua criadora (autor-modelo), quem, na confecção da boneca, confecciona também um leitor-modelo capaz de a interpretar a partir da analogia com sua autora, resgatando em Emília os discursos que Nastácia não enunciava. Por isso, Emília enuncia de forma muito autêntica e inovadora, o que também marca a sua diferenciação diante de seus pares, e, diferentemente de Nastácia, que também enuncia, Emília é ouvida. Por mais que o que ela diz seja caracterizado como "asneiras" pelos outros personagens, a boneca, por meio da enunciação, se faz ouvir e suas ideias são levadas a cabo, o que promove grande parte das aventuras narradas nos livros. Já Nastácia, quando enuncia, traz ideias de outros, que ouviu de sua mãe. Ela mesma não cria, só reproduz o que lhe foi dito. Para Bazerman (2006), a enunciação é uma forma de ação. Por meio de nossos textos, produzimos fatos sociais, "Cada texto bem-sucedido cria para seus leitores um fato social. Os fatos sociais consistem em ações sociais significativas realizadas pela linguagem, ou atos de fala" (BAZERMAN, 2006, p. 22).

Partindo desse pressuposto, a situação de Emília e Nastácia diante do mundo e de seus problemas é bastante diferente. Enquanto Nastácia fica, em grande parte no Sítio, mais especificamente, na cozinha, exclamando seus medos e superstições e, quase sempre, apresentando um ponto de vista tradicionalista e pacífico diante das circunstâncias, Emília apresenta uma perspectiva arrojada e moderna diante dos fatos. Viaja por diversos lugares reais e imaginários, se ocupa dos problemas que rodeiam o Sítio e o que está fora dele, seja no mundo da fantasia ou no mundo real, sempre procurando uma solução. Este é o caso do livro A chave do tamanho (2008), o qual se passa no contexto da Segunda Guerra Mundial (1939-1945). Diante das notícias do conflito na Europa, Dona Benta fica muito preocupada e apreensiva, o que "andava a anoitecer o Sítio do Picapau, outrora tão 
alegre e feliz" (LOBATO, 2008, p. 15). Por isso, Emília, diferentemente de todos os outros personagens, resolve, por si, dar um fim no conflito e "desligar" a chave da guerra. Com a ajuda do pó de pirlimpimpim ela viaja até o fim do mundo e encontra a Casa das Chaves, porém, como não havia nenhuma referência em qual seria a chave da guerra, Emília, seguindo o método de experimentação utilizado pelos sábios, acaba desligando a chave que regula o tamanho dos seres humanos, o que quase provoca o fim da Humanidade, mas nas palavras da boneca,

- Sim, eu mexi na chave do tamanho e todas as criaturas vivas ficaram pequenas porque seria absurdo haver uma chave só para minha pessoa. Se houvesse uma chave para cada pessoa, nesta sala deviam existir dois bilhões de chaves, porque a população do mundo é de dois bilhões de pessoas. Logo, a mesma chave serve para todas as pessoas. Logo, toda Humanidade está "reduzida" - e impedida de fazer guerras. - Uf! Acabei com a guerra! Viva! Viva! (LOBATO, 2008, p. 19).

Enquanto Emília resolve de forma simplista e atrevida os problemas, Nastácia mostra uma perspectiva tradicionalista diante das circunstâncias da vida, apresentando dificuldade de lidar com o novo:

- E Tia Nastácia? - perguntou Emília - que está fazendo lá, escarrapachada e muda?

Dona Benta explicou que a negra não se conformava com a Ordem Nova e perdera o interesse em tudo. Vivia assim, escarrapachada no chão, de mão no queixo, pensando naquele misterioso transtorno do mundo. Tão abatida que nem dava resposta ao que lhe perguntavam (LOBATO, 2008, p. 84).

Mais um exemplo da analogia entre as duas personagens no que concerne à forma como as duas encaram os problemas ao seu redor é a conclusão paradoxal que cada uma apresenta diante da Nova Ordem de tamanho humana nesta narrativa: 
[...] o que agora aconteceu alcançou a Humanidade inteira. Qual é sua ideia, Tia Nastácia?

- Ah, eu penso que o mundo acabou - o mundo antigo. Nós morremos todos, sem saber, e estamos no céu. Somos almas do outro mundo [...] Ou então é sonho. Se é sonho, quando acordamos tudo se acaba e a vida de antes começa outra vez. E se é morte, é morte e pronto (LOBATO, 2008, p. 92).

- E Tia Nastácia acha que é sonho - continuou Dona Benta.

- Sonho o nariz dela! - berrou Emília - Parece incrível que não percebam o que houve. O mundo é uma máquina de mil peças. Com certeza alguma peça saiu do lugar - é isso (LOBATO, 2008, p. 94).

Se Nastácia analisa as coisas pelo viés da religiosidade e da crendice popular, Emília tenta seguir pelo viés da ciência e do conhecimento. Ela busca um olhar numa inovadora perspectiva lógica para solucionar os problemas, o que nos leva a questionar sua principal característica: "torneirinha de asneiras". Em diversos momentos de sua enunciação, Emília é adjetivada por torneirinha de asneiras, o que pode até provocar no leitor um sentido de que o que a boneca fala é burrice, ignorância ou que não apresenta lógica, porém à medida em que conhecemos as narrativas e a boneca, temos que procurar um novo efeito para essa locução adjetiva, pois em seus enunciados temos um sujeito entrecruzado por diferentes vozes e discursos em oposição, que rompem com a tradição e colocam em xeque a ideologia dominante. E, para seus interlocutores, o que resta é colocála no patamar de "asneirice", tentando manter a ordem das coisas como estão dadas.

Assim, a torneirinha de asneiras é, na verdade, um sujeito que rompe a ordem do mundo. Emília traz, por meio de sua voz, a novidade de perspectiva e a resistência para o que está posto. A noção de resistência é profundamente discutida por Foucault (1926) em seus apontamentos. Segundo Bampi (2002), em seus últimos trabalhos Foucault conecta 
a ideia de resistência do sujeito ao cuidado de si. Para Padro Filho (2016), ao discutir sobre o sujeito e o poder, Foucault propõe que um dos efeitos da subjetivação do sujeito se dá pelo exercício de resistência. Dialogando com a concepção foucaultiana de resistência, Emília se subjetiva, tornando-se sujeito de si por exercícios de resistir ao que está dado e posto. Suas soluções se encontram no campo da experimentação e do avanço, enquanto Nastácia se pauta no que já conhece, o que já é familiar e, dessa forma, é difícil de lidar com a mudança, com o novo. As duas protagonizam um contraponto de submissão e emancipação. Por isso, em mais um aspecto de encontro das duas personalidades, para Emília, quem é "asneirenta" é tia Nastácia:

- Pois cá comigo - disse Emília - só aturo essas histórias como estudos da ignorância e burrice do povo. Prazer não sinto nenhum. Não são engraçadas, não têm humorismo. Parecem-me muito grosseiras e bárbaras, coisa mesmo de negra beiçuda como Tia Nastácia. Não gosto, não gosto e não gosto... (LOBATO, 2011, p. 28).

Com isso, podemos traçar mais um paralelo entre as duas personagens: o de tradição e modernidade. Como dito anteriormente, Nastácia pouco enuncia e apresenta em seus posicionamentos um caráter bastante tradicionalista, de manutenção de atitudes, pensamentos e crenças, enquanto Emília sempre apresenta inovações. A boneca, em seus enunciados, está sempre questionando e refletindo suas atitudes e pensamentos, em busca de novas soluções para o que já é tido como certo. Esse traço de Emília dá sustentação para dois livros: A reforma da natureza (1941) e A chave do tamanho (1942). Nessas duas narrativas, Emília decide questionar e mudar o que está posto e acaba promovendo "revoluções" na humanidade e, por mais que nem todas as suas ideias saiam como o esperado, ela continua tentando e questionando o que pode ser melhor. Segundo Hall 
(2006), a grande diferença entre a tradição e a modernidade é que esta é "uma forma altamente reflexiva da vida" (HALL, 2006, p. 15), enquanto aquela é uma necessidade de manutenção e valorização de experiências passadas. Assim, a partir dessa concepção de tradição e modernidade, podemos enxergar nas duas personagens esses dois potenciais postos em relação.

Entendendo a língua como reflexo da sociedade e todo seu funcionamento dinâmico, temos em Nastácia uma polifonia que marca uma ideologia de repressão, submissão. O negro em nossa sociedade, até o final do século XIX, só tinha o espaço social de escravo. Logo, seu campo discursivo não se constituía de um conhecimento técnico e científico, não participava da vida cultural e intelectual. Por isso, suas narrativas e conhecimentos partem de uma prática: sua discursividade é constituída por um conjunto de vozes que se encontravam na mesma condição. Contrariamente, Emília enuncia a partir de outra situação. A boneca tem acesso ao conhecimento científico e cultural que Dona Benta tanto valoriza e tenta passar para seus netos e todos os moradores do Sítio. Assim, sua constituição se dá em outra dinâmica polifônica, contrária à de Nastácia.

Um outro aspecto que concorre para esse embate discursivo é que Nastácia já é uma "velha de setenta anos" (Lobato, 2005, p. 26) no livro Reinações de Narizinho (2005), enquanto Emília, como sujeito discursivo, que enuncia, nasce nessa mesma história. Assim, Nastácia tem todo seu universo constituído por uma história e vozes do século XIX, sua ignorância é herança. Já a boneca nasce em pleno século XX, período em que a narrativa foi publicada pela primeira vez. Assim, sua suposta ignorância é característica de avanço, aquisição do novo conhecimento, de resistência. No livro A Chave do Tamanho, Emília descreve essa dificuldade das pessoas mais velhas em se adaptarem às ideias novas: "Mas acha que as nossas velhas ideias tornar-se-ão inúteis nesse mundo novo?" diz 
Dona Benta. "Inúteis propriamente não. Mas têm de ser revistas e reformadas", responde Emília (LOBATO, 2008, p. 87).

A dualidade que caracteriza as duas personagens é um arranjo estético produzido pelo criador das duas: Monteiro Lobato, e é, exatamente, em nosso ver, a marca da relação de autoria e obra entre elas no interior das narrativas. Lobato atribui a condição de autora/criadora para Nastácia na confecção de Emília no interior da obra, permitindo que a boneca se transforme na voz, no texto que denuncia tudo que Nastácia, em sua condição, não podia ser. Emília é a enunciação de Nastácia. Porém, sua obra ganha vida a ponto de ficar incontrolável, deixa de ser boneca, reflexo humano, e passa a ser gente. Assim, Emília, criatura de Nastácia, contrapõe tudo que sua criadora é. Emília se apresenta como a oposição de Nastácia, sendo assim tudo o que ela não queria ou não podia ser.

Para Foucault (1999, p. 9), em nossa sociedade toda produção de discurso, por meio dos textos, é "controlada, selecionada, organizada e redistribuída por certo número de procedimentos que têm por função conjurar seus poderes e perigos, dominar seu acontecimento aleatório, esquivar sua pesada e temível materialidade". Em sua condição de negra, vinda de um regime escravocrata, Nastácia não teria como movimentar-se socialmente, ocupar outros espaços sociais, a não ser o de "negra de estimação". Ao recriarse na boneca, ela vê todo um novo universo a ser explorado, todo um mundo a conhecer e a confrontar. Afinal, agora, na condição de boneca, ela pode confrontar e resistir às imposições.

Nesta análise procuramos, de forma breve, visto a dimensão da saga e as possibilidades de enunciados para serem analisados, demonstrar como a função-autor ou o gesto de autoria pode ser possível na relação das personagens Tia Nastácia e Emília. Sob diversos aspectos, podemos constatar que há entre as duas analogias que as aproximam, 
no confronto ideológico, esses dois sujeitos num diálogo constante. Dessa forma, além de levantarmos uma discussão sobre os processos de aproximação das duas, discutimos a possibilidade de leitura da boneca como um texto produzido por Nastácia dentro das narrativas como representação de si e, no caso analisado, como representação do que poderia ser.

A possibilidade dessa perspectiva sobre as personagens instaura uma nova visão sobre a obra em si. Não enxergar Emília como um sujeito que desrespeita Nastácia, mas a refuta, numa tentativa de negar quem ela é afinal e, de se distanciar dessa triste condição social imputada aos negros em nossa sociedade, abrindo um horizonte ilimitado de conhecimento, aventura, descoberta, resistência e liberdade.

\section{Referências}

BAKHTIN, Mikhail Mikhailovitch; VOLÓCHINOV, Valentin. Marxismo e filosofia da linguagem. Tradução Michel Lahud e Yara Frateschi Vieira. São Paulo: Hucitec, 2014. . Estética da criação verbal. Tradução Paulo Bezerra. São Paulo: Martins Fontes, 2003.

BAMPI, Lisete. Governo, subjetivação e resistência em Foucault. Revista Educação e Realidade, v. 27, 2002. Disponível em: <http://seer.ufrgs.br>. Acesso em: 09 de nov. 2017. BAZERMAN, Charles. Gêneros textuais, tipificação e interação. Tradução Judith Chambliss Hoffnagel. São Paulo: Cortez, 2006.

COX, M. I. P. LIMA, C. R. Z. O colocador de pronomes: Monteiro Lobato e a questão da língua brasileira. Revista da ABRALIN, v. 16, 2017. Disponível em:

<http://revistas.ufpb.br>. Acesso em: 09 de nov. 2017.

ECO, Umberto. Lector in fabula, a cooperação interpretativa nos textos narrativos. Tradução Attílio Cancian. São Paulo: Editora Perspectiva, 1986. 
FOUCAULT. Michel. O que é um autor? Tradução Antônio Fernando Cascais e Eduardo Cordeiro. Lisboa: Passagens/Vega, 2002.

. A ordem do discurso. Tradução Laura Fraga de Almeida Sampaio. São Paulo: Edições Loyola, 1999.

HALL, Stuart. A identidade cultural na pós-modernidade. Tradução Tomaz Tadeu da Silva e Guacira Lopes Louro. Rio de Janeiro: DP\&A, 2006.

LOBATO, Monteiro. Reinações de Narizinho. São Paulo: Editora Globo, 2005.

. A chave do tamanho. São Paulo. Editora Globo. 2008.

Emília no país da gramática. São Paulo. Editora Globo. 2009.

Histórias de tia Nastácia. São Paulo. Editora Globo. 2011.

ORLANDI, Eni P. Interpretação autoria, leitura e efeitos do trabalho simbólico. Campinas, SP: Pontes Editores, 2007.

PÊCHEUX, Michel. Semântica e discurso: uma crítica à afirmação do óbvio. Tradução Eni P. Orlandi. Campinas: Editora da UNICAMP, 1995.

PRADO FILHO, Kleber. Estetização da subjetividade: formas contemporâneas de cuidado e produção de si mesmo. In: Simpósio Mundial de Estudos da Língua Portuguesa (SIMELP), 48, 2016, Santarém (Portugal). Disponível em: <http:// http://simelp.ese.ipsantarem.pt>. Acesso em: 03 de nov. 2017.

VELOSO, A. N. S. Perfis femininos em livros infantis de Monteiro Lobato (1920-1940). 2013. Dissertação (Educação) - Faculdade de Educação, Universidade do Rio de Janeiro. Rio de Janeiro. 2013.

Recebido em 21 de maio de 2019.

Aceite em 30 de outubro de 2019. 